switch must be increased while still keeping its magnetic response at an adequate level. There is no lack of challenges ahead, but Kiselev et al. ${ }^{1}$ have shown that we are on the right path.

Jonathan Sun is in the IBM Research Division,

Thomas J. Watson Research Center, PO Box 218,

Yorktown Heights, New York 10598, USA.

e-mail:jonsun@watson.ibm.com

1. Kiselev, S. I. et al. Nature 425, 380-383 (2003).
2. Slonczewski, J. C. J. Magn. Mag. Mater. 159, L1-L7 (1996); 195, L261-L268 (1999).

3. Berger, L. Phys. Rev. B 54, 9353-9358 (1996).

4. Bazaliy, Y. B., Jones, B. A. \& Zhang, S.-C. Phys. Rev. B 57, R3213-R3216 (1998).

5. Sun, J. Z. J. Magn. Mag. Mater. 202, 157-162 (1999).

6. Tsoi, M. et al. Phys. Rev. Lett. 80, 4281-4284 (1998).

7. Wegrowe, J. E., Kelly, D., Jaccard, Y., Guittienne, Ph. \& Ansermet, J.-Ph. Europhys. Lett. 45, 626-632 (1999).

8. Katine, J. A., Albert, F. J., Buhrman, R. A., Myers, E. B. \& Ralph, D. C. Phys. Rev. Lett. 84, 3149-3152 (2000)

9. Tsoi, M. et al. Nature 406, 46-48 (2000).

Plant biology

\title{
Water gate
}

\section{N. Michele Holbrook and Maciej A. Zwieniecki}

Flooding reduces the ability of roots to absorb water. The molecular basis for this paradox involves the regulation of water-channel proteins by the $\mathrm{pH}$ inside root cells.

$\mathrm{P}$ lants are among the thirstiest of creatures. Of the more than 60 trillion tonnes of water that cycles each year from the land to the atmosphere, nearly two-thirds passes through the bodies of living land plants ${ }^{1}$. Plants require these large amounts of water because their mode of acquiring carbon dioxide exposes their interior to the drying power of the atmosphere. Without water, forests become stunted, agricultural yields decline, and house plants shrivel and die. Yet, as is so often the case, too much of a good thing can also be a problem. Flooding typically reduces both photosynthesis and growth, and, in the short term, can even cause plants to wilt. This paradox of famine in the midst of plenty arises from the fact that flooding causes roots to become less permeable to water. On page 393 of this issue ${ }^{2}$, TournaireRoux and colleagues elucidate a cascade of molecular events that links the low oxygen levels associated with flooding, via changes in the $\mathrm{pH}$ inside cells, to this decrease in root permeability.

The large-scale movement of water from roots to leaves takes place almost entirely through spaces that are not bounded by cell membranes. Only as water enters roots is there substantial evidence that this 'transpiration stream' flows through living cells. The ease with which water can traverse root cells is, to a large degree, governed by the presence of highly selective channel proteins known as aquaporins, specifically those of a subgroup known as 'plasma membrane intrinsic proteins' (PIPs). These proteins are present in the plasma membranes of root cells and enhance the membranes' permeability to water ${ }^{3}$.

Because of the key role of aquaporins in water uptake by roots ${ }^{4}$, changes in the conductance of individual water channels - a process referred to as 'gating' - are likely to be involved in mediating the effects of flooding. Previous studies have shown that aqua-

porins can be gated by various factors, including enzymatic modification with phosphate groups ${ }^{3}$, intracellular calcium levels ${ }^{5,6}$ and, most recently, protons ${ }^{5-8}$. But the molecular mechanisms that underlie the regulation of aquaporin permeability including how it might be connected to flooding - have until now remained elusive.

Gases diffuse around 10,000 times more slowly through water than through air, with the result that roots in flooded soils quickly become exposed to conditions of low oxygen. Early cellular responses to oxygen deprivation include a marked decrease in $\mathrm{pH}$ in the cell interior, or cytosol. Tournaire-Roux et al. ${ }^{2}$ have now investigated whether these changes are linked to changes in the permeability of roots to water. Using roots of the model plant Arabidopsis thaliana, the authors manipulated the $\mathrm{pH}$ in the cytosol of root cells in one of three ways: by decreasing the availability of oxygen; by inhibiting respiration; and by loading the roots with acid. In all cases, decreases in cytosolic $\mathrm{pH}$ were associated with a decrease in root permeability. Altering the $\mathrm{pH}$ outside root cells did not have this effect.

Do decreases in cytosolic $\mathrm{pH}$ alter root permeability by affecting the conductance of PIP-type aquaporins? To test this hypothesis, Tournaire-Roux and colleagues inserted aquaporins into the plasma membrane of immature frog eggs. Osmotic swelling assays showed that water influx through most PIPtype aquaporins was selectively blocked by cytosolic acidification. In contrast, the activity of an aquaporin from vacuoles (an intracellular compartment) was insensitive to changes in $\mathrm{pH}$. By using a series of mutant proteins, Tournaire-Roux et al. demonstrated that charged amino acids (particularly histidine at position 197) in the cytosolic vestibule of the aqueous pore are responsible for the observed $\mathrm{pH}$ sensitivity of the PIPs. These findings provide a detailed explanation for the mechanisms by which root permeability to water is downregulated in response to anoxia.

What is still unclear, though, is why a plant - flooded or otherwise - would ever choose to restrict water flow through its roots. Roots acclimate to waterlogged soils primarily by forming large gas-filled spaces in the root cortex that provide a lowresistance path for oxygen diffusion ${ }^{9}$. So the physiological significance of TournaireRoux and colleagues' findings may lie in the possibility that reductions in root permeability can enhance this morphological acclimation of flooded roots.

This may not be as far-fetched as it seems. Air spaces in the root are formed when specific cells in the root cortex undergo programmed cell death; the cue for this is a build-up of the gaseous hormone ethylene'. Flooding leads to an increase in ethylene concentrations in roots, both because anoxia activates an enzyme called ACC synthase, the key biosynthetic enzyme for ethylene, and because waterlogged soils retard the diffusion of the gaseous hormone away from the root. But ethylene accumulation is also affected by the rate at which ACC, the precursor to ethylene, is transported away from the roots in the transpiration stream ${ }^{10}$. So downregulation of root permeability could theoretically provide a mechanism that, by reducing the flow of water through roots, accelerates the build-up of ethylene and the transformation of the root into a form that is appropriate for dealing with flooding.

Whether or not this indeed occurs requires further experiments using the sort of genetically modified plants made possible by Tournaire-Roux and colleagues' findings. Plants with $\mathrm{pH}$-insensitive aquaporins could now be engineered, allowing researchers to test whether a decrease in root permeability is required to signal the need for the formation of air spaces. But for now, it is satisfying to see that the paradoxical thirstiness of flooded plants has been placed on firmer ground.

N. Michele Holbrook and Maciej A. Zwieniecki are in the Department of Organismic and Evolutionary Biology, Harvard University, 16 Divinity Avenue, Cambridge, Massachusetts 02138, USA.

e-mail:Holbrook@oeb.harvard.edu

1. Sack, L. \& Tyree, M. T. in Movement of Water and Carbohydrates in Plants: Integration of Long Distance Transport Processes (eds Holbrook, N. M. \& Zwieniecki, M. A.) (Academic, San Diego, in the press).

2. Tournaire-Roux, C. et al. Nature 425, 393-397 (2003).

3. Tyerman, S. D., Niemietz, C. M. \& Bramley, H. Plant Cell Environ. 25, 173-194 (2002).

4. Martre, P. et al. Plant Physiol. 130, 2102-2110 (2002).

5. Németh-Cahalan, K. L. \& Hall, J. E. J. Biol. Chem. 275, 6777-6782 (2000).

6. Gerbeau, P. et al. Plant J. 30, 71-81 (2002)

7. Yasui, M. et al. Nature 402, 184-187 (1999).

8. Zeuthen, T. \& Klaerke, D. A. J. Biol. Chem. 274, 21631-21636 (1999).

9. Buchanan, B. B., Gruissem, W. \& Jones, R. L. (eds) Biochemistry and Molecular Biology of Plants (Am. Soc. Plant Physiol. Rockville, 2000).

10. Bradford, K. J. \& Yang, S. F. Plant Physiol. 65, 322-326 (1980). 